\title{
Mechanical Properties and Microscopic Geological Features under Uniaxial Compression in Tight Reservoir
}

\author{
Dazhong Ren $\mathbb{D}^{1,2}$ Fu Yang, ${ }^{1}$ Zhonghui Duan, ${ }^{1}$ Tao Tian, ${ }^{1}$ Ran Zhou, ${ }^{3}$ and Dengke Liu ${ }^{4}$ \\ ${ }^{1}$ Key Laboratory of Coal Resources Exploration and Comprehensive Utilization, Ministry of Land and Resources, \\ Xian 710021, China \\ ${ }^{2}$ Shaanxi Key Laboratory of Advanced Stimulation Technology for Oil \& Gas Reservoirs, Xi'an Shiyou University, \\ Xi'an 710065, China \\ ${ }^{3}$ Drilling and Production Technology Research Institute, CNPC Chuanqing Drilling Engineering Company Limited, \\ Xi'an 710021, China \\ ${ }^{4}$ School of Human Settlements and Civil Engineering, Xi'an Jiaotong University, Xi'an 710054, China
}

Correspondence should be addressed to Dazhong Ren; petro_gas@163.com

Received 19 December 2020; Revised 11 January 2021; Accepted 15 January 2021; Published 28 January 2021

Academic Editor: Feng Xiong

Copyright (C) 2021 Dazhong Ren et al. This is an open access article distributed under the Creative Commons Attribution License, which permits unrestricted use, distribution, and reproduction in any medium, provided the original work is properly cited.

\begin{abstract}
In this study, to investigate the mechanical properties and microscopic geological features, a series of uniaxial compression, petrophysical properties, X-ray diffraction, elements, and conductivity tests were conducted. The results indicate that quartz and plagioclase are essential minerals determining Upper Triassic sandstone compositions, while quartz plays a dominant role in the Lower Permian sandstones. Due to microcracks, the relationships between porosity and permeability of Upper Triassic sandstones are better than those of Lower Permian sandstones. Observations have shown that silicon and aluminum are the main elements of those rocks. The rocks which have large porosity and permeability have a strong capacity of anticompression resistance. There are good consistencies between the mechanical behavior and the high proportion of rigid minerals. Similarly, the rocks which have abundant silicon and aluminum could better support the structural integrity of rocks. High pore structure heterogeneity and abundant clay minerals have positive influence on the mechanical resistance. Shales have distinct plastic deformation features when compared with the sandstones.
\end{abstract}

\section{Introduction}

Cores are confined to a stress circumstance in the oil or gas reservoir $[1,2]$. Field monitoring suggests that stresses of cores, which are rarely axisymmetric, increase with depth. Due to the differences in petrophysical properties, minerals, elements, and conductivity, cores have different geological features [3-5]. Many defects, such as fissures and fractures, existed in cores, and those geological features have a significant impact on the formation of the defects [6]. Understanding the mechanical properties of cores is essential in dealing with reservoir reformation. Therefore, the relationships between mechanical properties and geological characteristics attracted much attention, and the findings have been well documented experimentally, analytically, and numerically [7-10].
To figure out the mechanical properties of cores, uniaxial compression experiments have been intensively performed to investigate the core's mechanical characteristics under different stress states [11-13]. After the pioneer who conducted the true uniaxial experiments in the 1970s, various similar investigations were performed under quasistatic uniaxial confinement [14-16]. Some scholars have studied the defect (especially features) behaviors of cores and their relationships with geological features $[17,18]$. However, more detailed research is required because the minerals, elements, and conductivity that impact the crack of cores could still be a myth.

The Ordos Basin of China is rich in sandstones (Figure 1) and is mainly distributed in the Upper Triassic Formation and Lower Permian Formation [19]. However, sandstones' geological conditions in different areas are involved, revealing that 


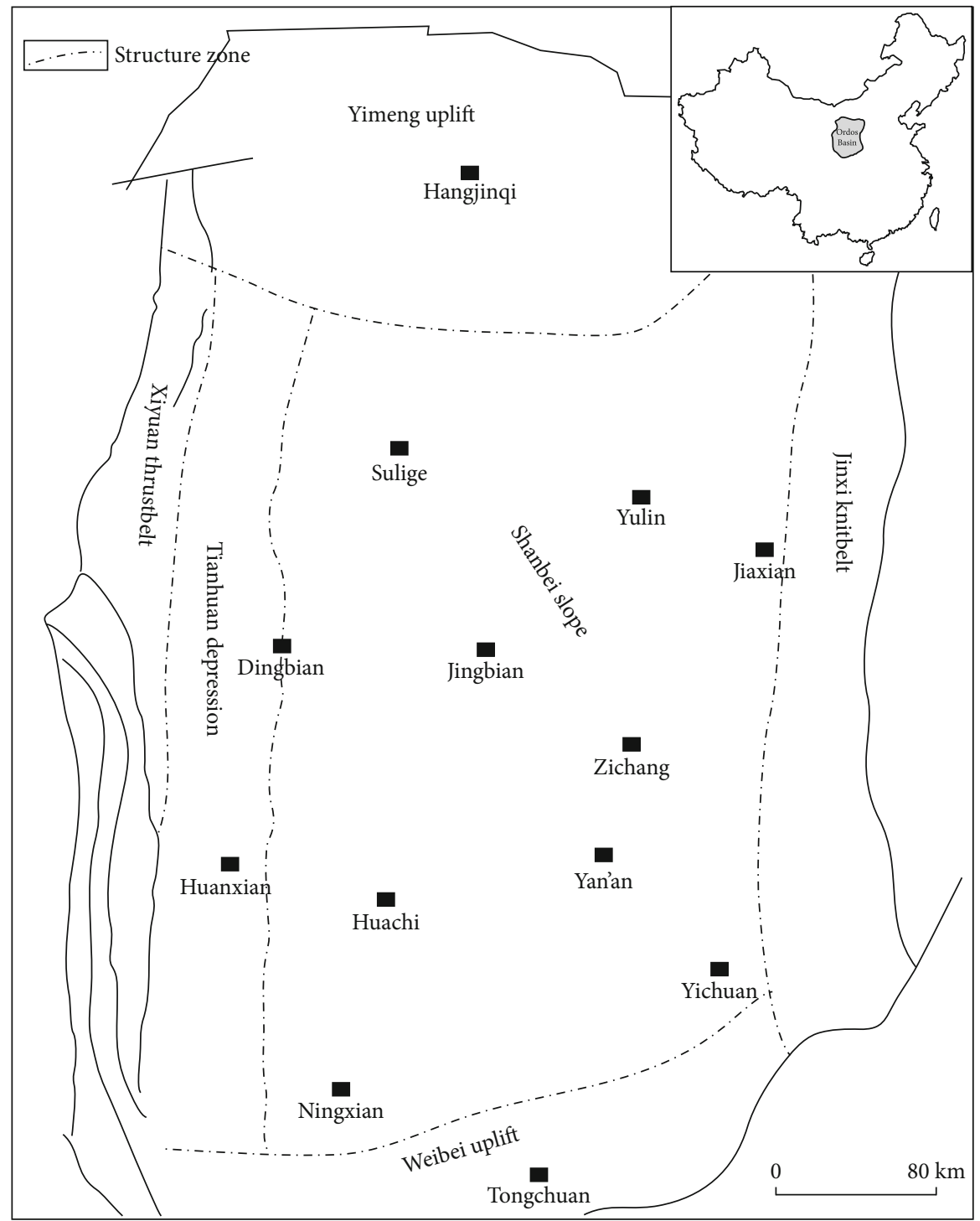

FIgURE 1: Geological setting of the Ordos Basin.

the mechanical properties may vary a lot $[20,21]$. Owing to the differences, it is vital to suggest the mineral composition, elements, and conductivity of tight sandstones in different areas, and the comparison of those two kinds of rocks from different formations has great significance. Besides, those cores' mechanical properties are quite different, and the rock deformation's underlying mechanisms still need to be investigated.

Therefore, in the present study, the physical properties, $\mathrm{X}$-ray diffraction, element composition, and rock-electrical experiments were performed on the Chang 7 segment's shales. The mechanical properties, including stress and strain measurements, were also conducted. Finally, how geological properties impact the mechanical features were investigated. Special attention was paid to the governing factors on the rock ruptures and the cracking thresholds of different core types.

\section{Test Methodology}

2.1. Physical Properties. The physical properties here were defined as porosity and permeability. After being washed with oil, dried, and vacuumed, the cores were put into the HKC-2 and HBSST-3 instruments for porosity and permeability determination, respectively. The samples are of cylinder shape with a diameter of $2.5 \mathrm{~cm}$ and a length of 4.6$4.8 \mathrm{~cm}$. The porosity was based on the volumetric method, and the permeability was conducted by pulse amplifier. Helium served as the medium.

2.2. $X$-Ray Diffraction. The samples were first dried at $60^{\circ} \mathrm{C}$ and $40 \%$ humidity for $48 \mathrm{~h}$ and then crushed under $40 \mu \mathrm{m}$ and put into the drying chamber for test waiting. Based on the $\mathrm{K}$ value method, which is mainly concerned with the relationships between characteristic peak intensity in the 


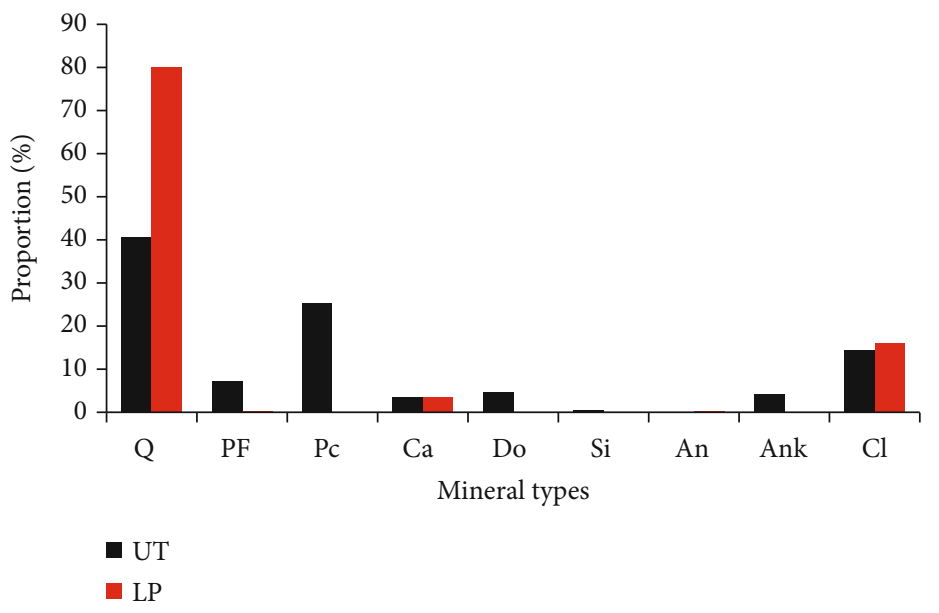

FIgURe 2: XRD results of the sandstones from two different strata. UT: Upper Triassic; LP: Lower Permian; Q: quartz; PF: potassium feldspar; Pc: plagioclase; Ca: calcite; Do: dolomite; Si: siderite; An: anatase; Ank: ankerite; Cl: clay.

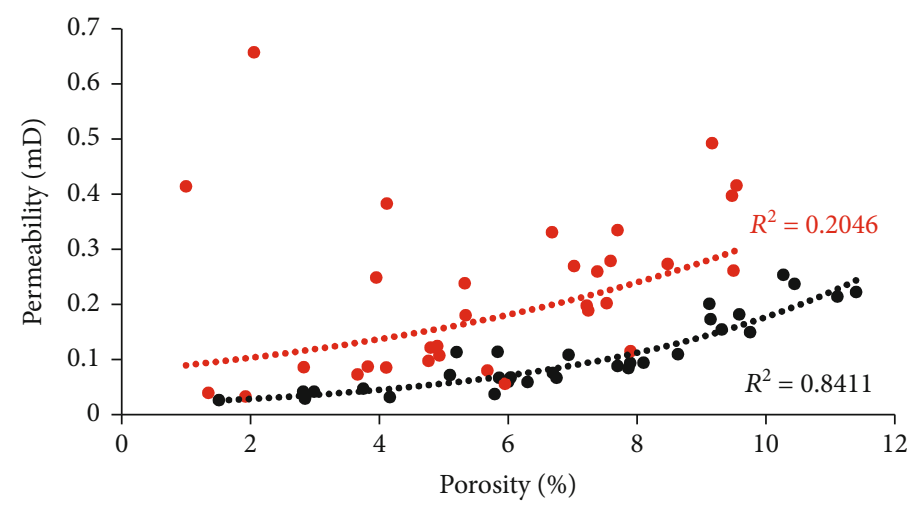

- UT

- LP

FIGURE 3: Relationship between porosity and permeability. UT: Upper Triassic; LP: Lower Permian.

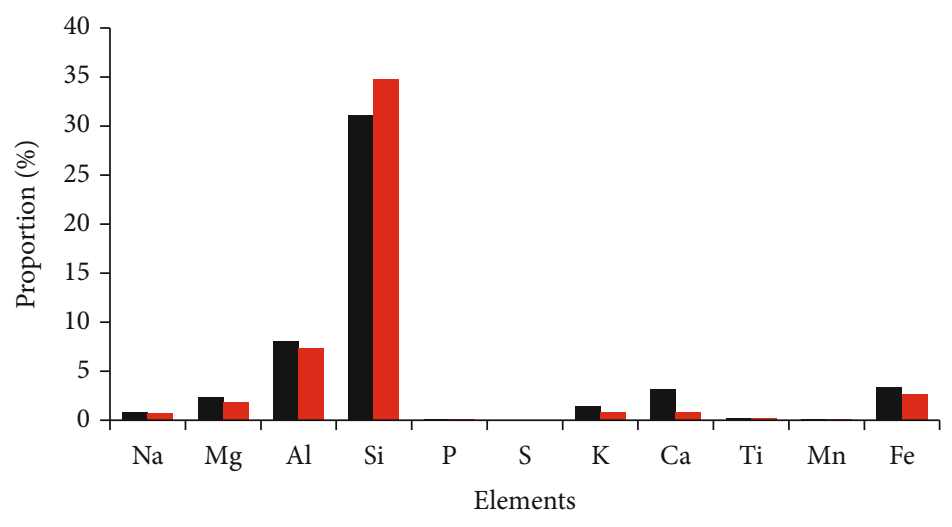

- UT

- LP

FIgure 4: Element results of the sandstones from two different strata. Na: sodium; Mg: magnesium; Al: aluminum; Si: silicon; P: phosphorus; S: sulfur; K: potassium; Ca: calcium; Ti: titanium; Mn: manganese; Fe: ferrum. 


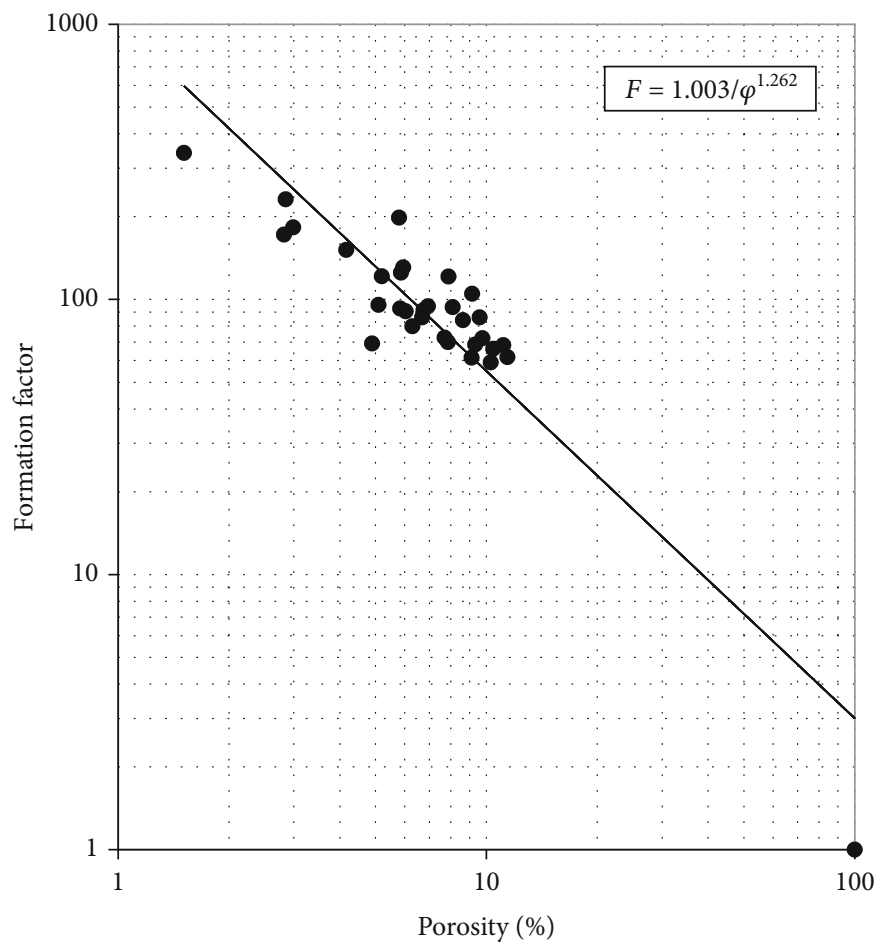

(a)

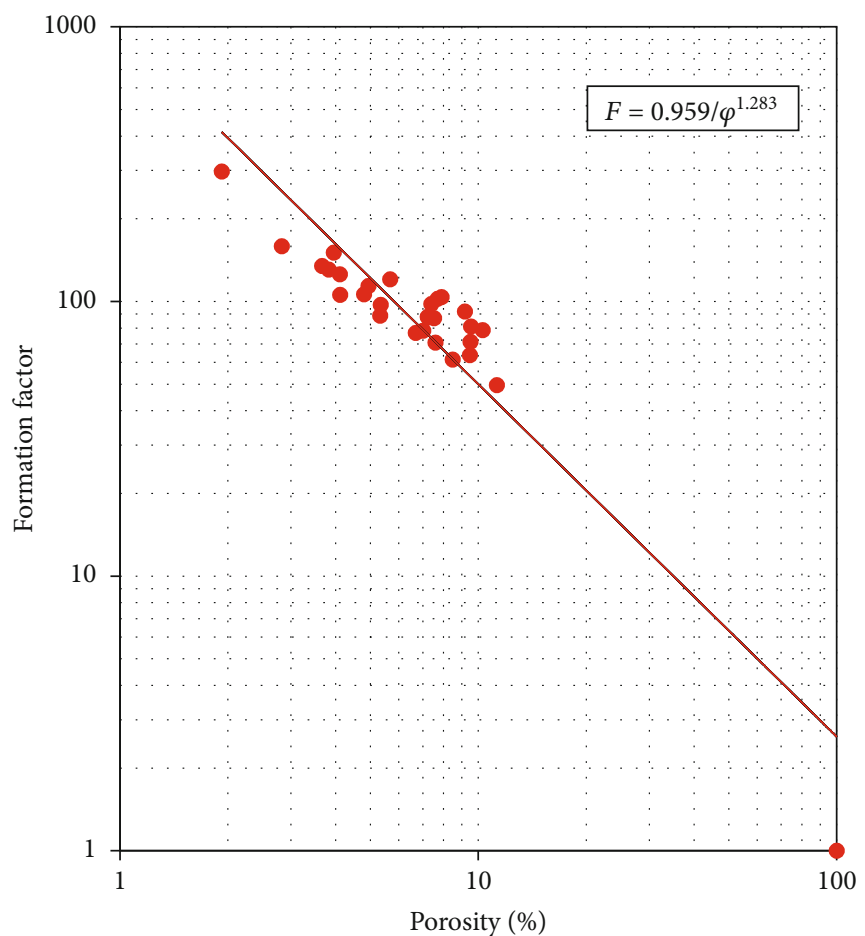

(b)

FIGURE 5: Relationship between porosity and formation factor of (a) Upper Triassic and (b) Lower Permian sandstones.

spectrum and mineral composition, the mineral patterns were determined by the Rigaku SmartLab9 X-ray diffractometer.

2.3. Major and Trace Elements. The major and trace elements were measured with an EDX3600B energy-dispersive X-ray fluorescence spectrometer. Similar to X-ray diffraction, the samples were put into the environment with $23^{\circ} \mathrm{C}$ temperature and $40 \%$ relative humidity.

2.4. Rock-Electrical Tests. A ZL5 Intelligent LCR measuring instrument and an AG285 electronic balance were used as the apparatus with $25^{\circ} \mathrm{C}$ temperature and $53 \%$ relative 


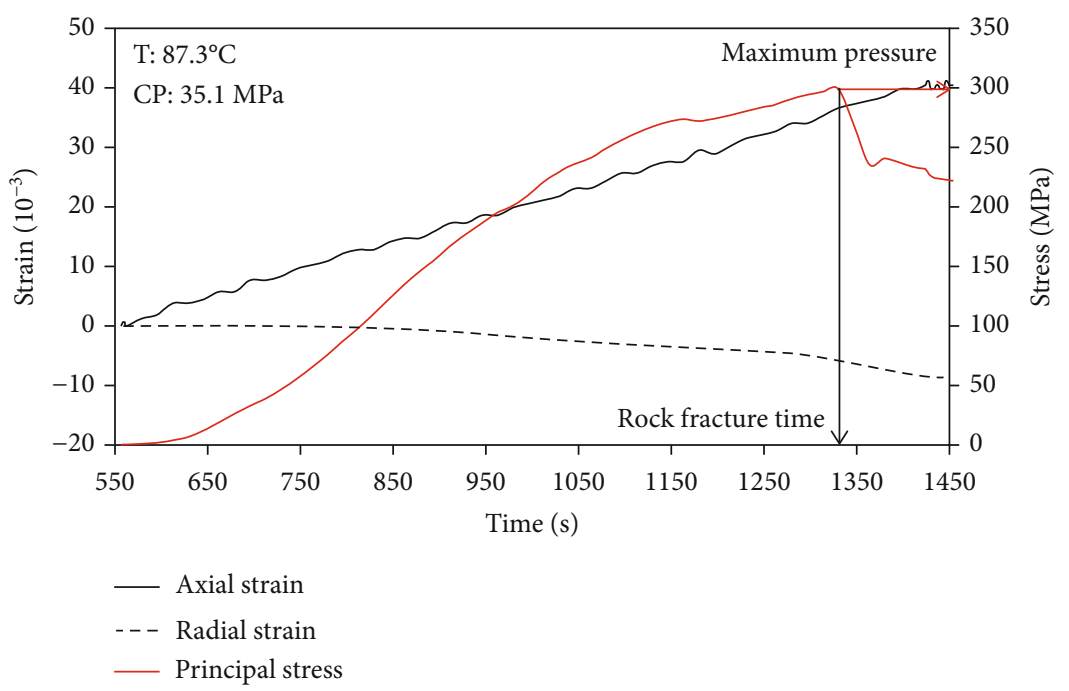

(a)

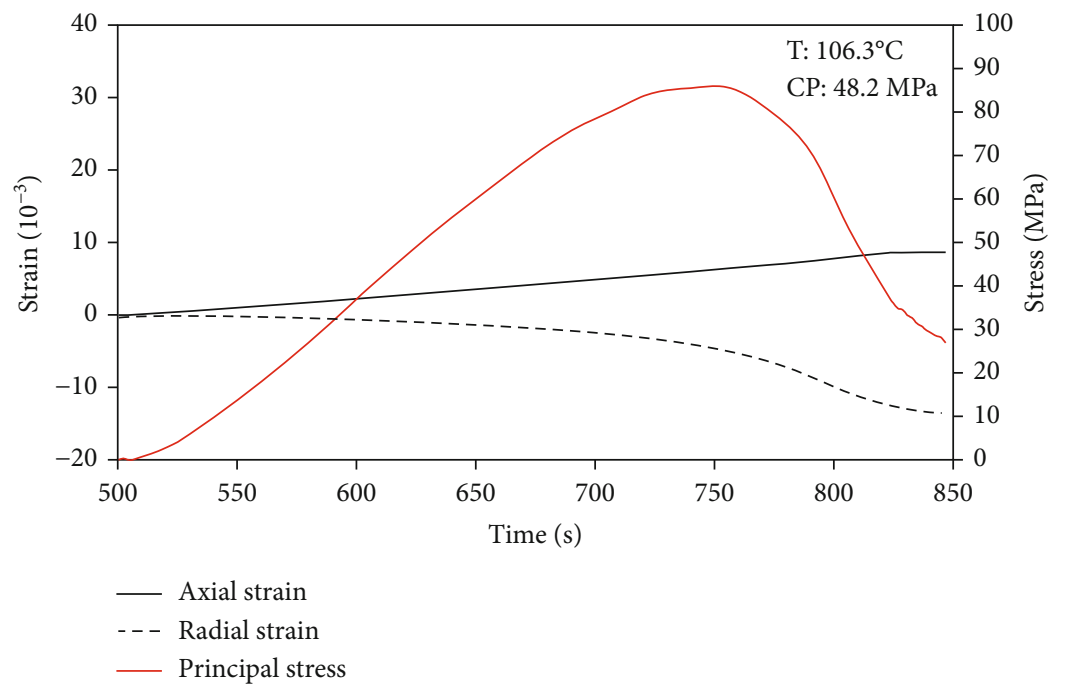

(b)

Figure 6: Dynamic stress and strain history: (a) Upper Triassic (2\#) and (b) Lower Permian sandstones (5\#), exemplarily shown. T: temperature; CP: confining pressure.

humidity. The salinity of the brine is $4 \times 10^{4} \mathrm{mg} / \mathrm{L}$ with the $\Omega \cdot \mathrm{m}$ of the water resistivity in $25^{\circ} \mathrm{C}$ temperature. The resistivity of the saturated cores was then determined, and the porosity was gathered from Section 2.1. The formation factor $F$, cementation index $m$, and saturation index $n$ were simulated by the relationship between resistivity, porosity, and saturation based on the Archie equation [22].

2.5. Uniaxial Compression Experiments. The cores were sealed into the chamber, and before the tests, two rigid metallic plates were placed on two ends to reduce the friction effect when loading was applied. The tests were performed with $35 \mathrm{MPa}$ of ambient pressure and $85^{\circ} \mathrm{C}$ of environmental temperature. During the experiments, the force was imposed on the samples at a constant speed, and the force was gradually reduced when the cores were cracked. A linear variable differential transformer was applied to determine the deformation of samples.

\section{Results}

3.1. Mineral Compositions. XRD was used to study rock mineral compositions (Figure 2) [23-25]. The result indicates that the main mineral types of Upper Triassic sandstones include quartz, plagioclase, clay, etc., while those of Lower Permian sandstones include quartz, calcite, and clay. Quartz and feldspar are the main detrital minerals in Upper Triassic sandstones, and so many kinds of interstitial minerals, such as calcite, dolomite, siderite, ankerite, and clay, occluded the pore spaces. The mineral types of Lower Permian sandstones are relatively monotonous. Quartz is the only detrital mineral and calcite and clay are the main interstitial minerals, while anatase is in trace amounts.

3.2. Petrophysical Properties. The petrophysical properties of the samples are shown in Figure 3. The averaged porosity of Upper Triassic and Lower Permian sandstones is 6.93\% and 

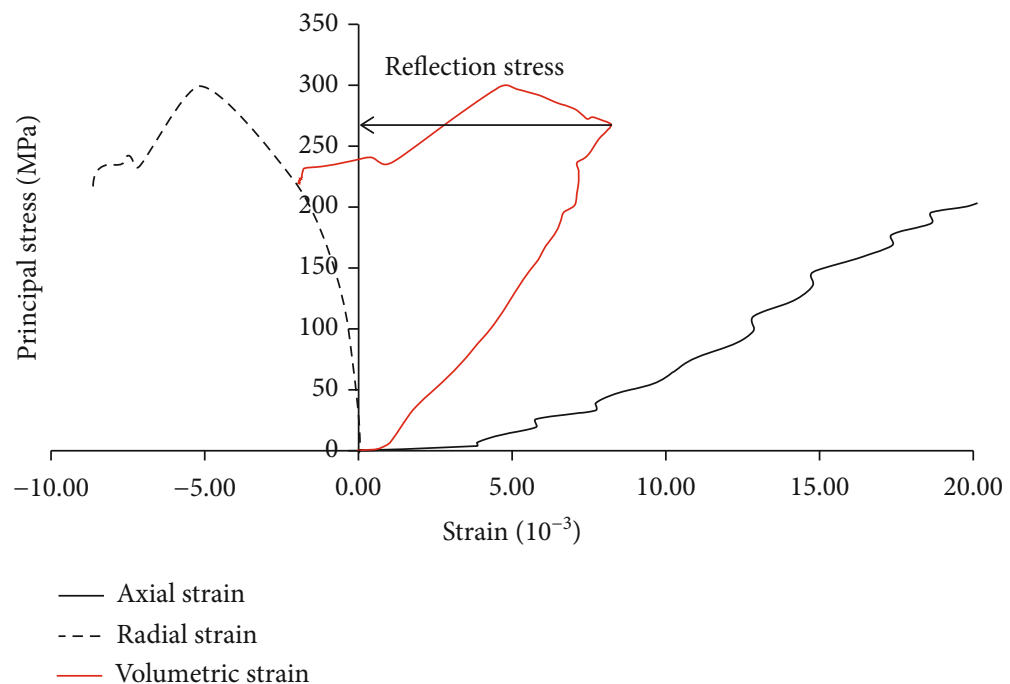

(a)

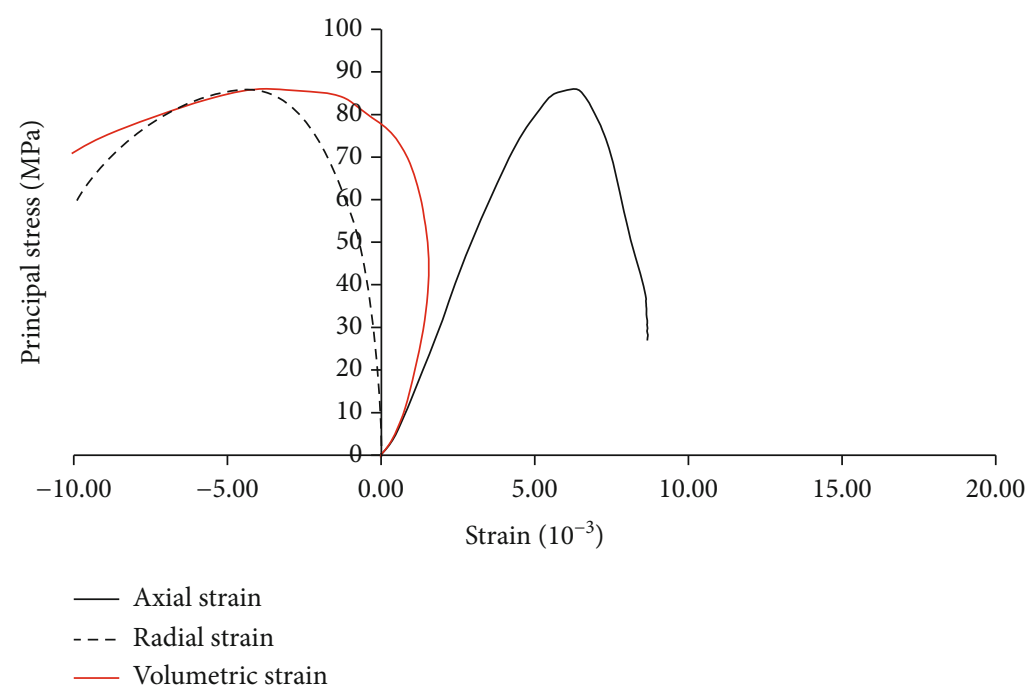

(b)

FIGURE 7: Stress and strain history: (a) Upper Triassic (2\#) and (b) Lower Permian sandstones (5\#), exemplarily shown.

$5.71 \%$, respectively. The averaged permeability of Upper Triassic and Lower Permian sandstones is $0.11 \mathrm{mD}$ and $0.22 \mathrm{mD}$, respectively. The reasons for these phenomena might be the depth differences: deeper burial, which corresponds to more considerable stress, would decrease the pore spaces while creating more microcracks. The burial depth of Lower Permian sandstones is more profound than Upper Triassic sandstones, so the former has lower porosity and higher permeability.

The relationship between porosity and permeability is approximately exponential lines in the coordinate system $[26,27]$. There is an excellent positive correlation for Upper Triassic sandstones, while the $R$-squared for Lower Permian sandstones is very low. Too many microcracks lead to high permeability and low porosity, which may result from abundant rigid minerals and deeper burial depth (Figure 3).
3.3. Element Characteristics. According to the elemental analysis results (Figure 4), silicon, which indicates detrital minerals, such as quartz, has the highest content in two strata. Aluminum, which is associated with feldspar and clay, comes second. The amounts of all types of elements in Upper Triassic sandstones are higher than those in Lower Permian sandstones, except silicon.

3.4. Rock-Electrical Results. Because the rock-electrical parameter of sandstones has a significant impact on the formation properties, it is necessary to extract the rock-electrical model features [28-32]. The formation factor, which was determined by the ratio of saturated cores and water resistivity, averaged 111.10 and 104.33 for Upper Triassic and Lower Permian sandstones, respectively. The relationships between porosity and formation factor in the log-log coordinate can be used for the rock-electrical parameter with the help of 


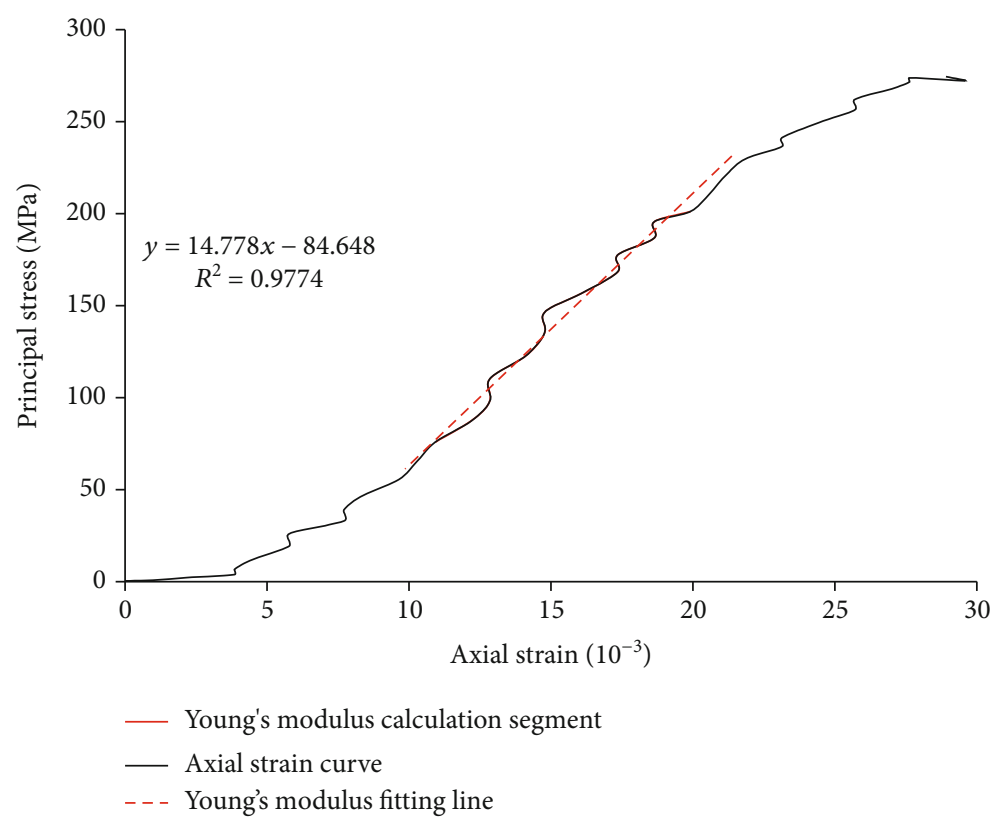

(a)

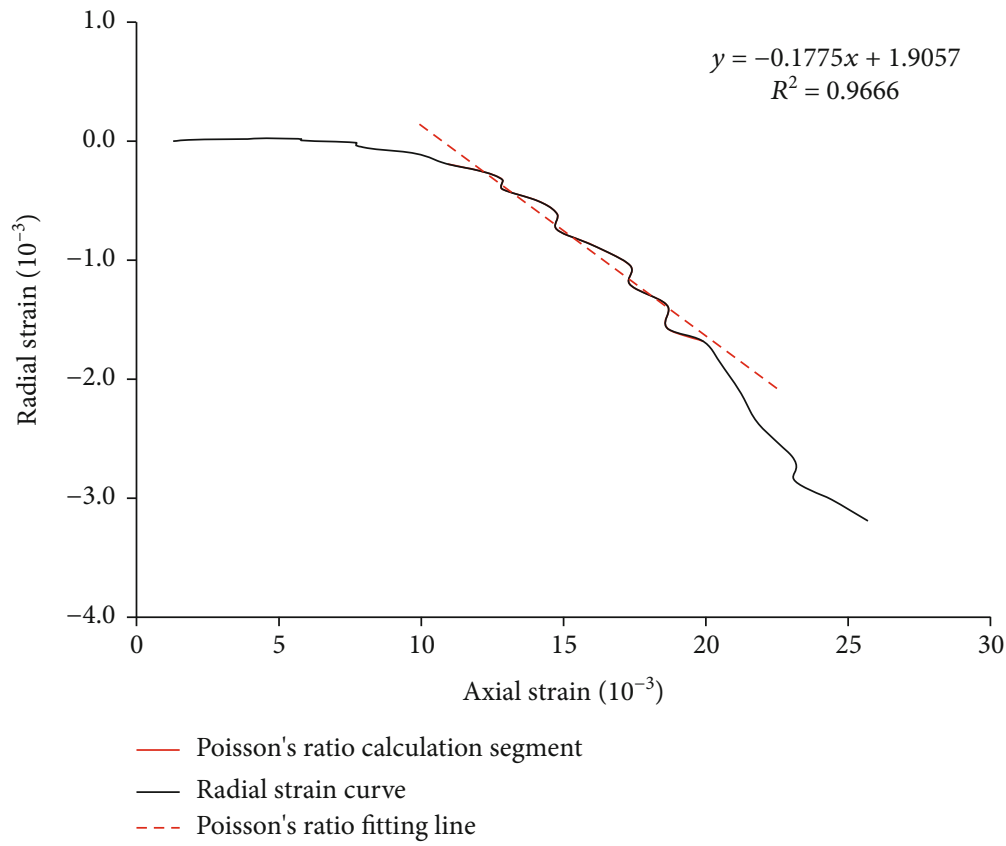

(b)

FIgURE 8: The calculation procedure of (a) Young's modulus and (b) Poisson's ratio.

the Archie equation, and for the Upper Triassic and Lower Permian sandstones, the averaged $m$ is equal to 1.262 and 1.283 and an equivalent to 1.003 and 0.959 , respectively (Figure 5). Highmhas a corresponding complex pore structure; therefore, those two sandstones may have a similar pore-throat ratio.

3.5. Uniaxial Compression Data. The compression is defined as positive in our research, and the signals obtained by uniaxial compression tests with unique temperature and confining pressure are exemplarily shown in Figure 6. The Lower Permian sandstones are easy to crack when compared to
Upper Triassic sandstones. Detailed figures and analysis are shown in Figure S1, Table S1, and Discussion.

\section{Discussion}

4.1. Compression Data Interpretation. The interpretation of signals of compression is necessary to achieve the mechanical rock properties. The relationships among principal stress, axial strain, and radial strain are obtained and shown in Figure 7 and Figure S2. The axial and radial strains increase with the principal stress increase, while the volumetric strains show a hysteresis trend. 


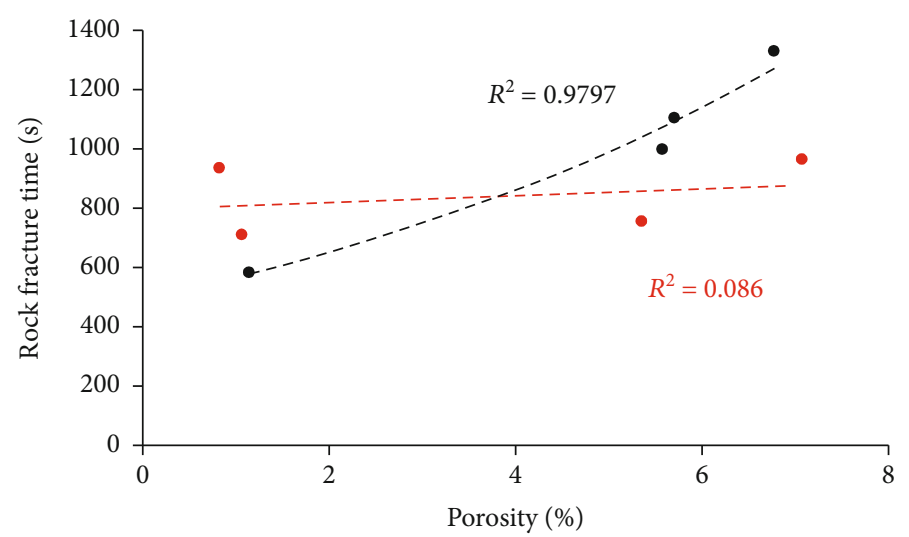

$$
\begin{aligned}
& \text { - UT } \\
& \text { - LP }
\end{aligned}
$$

(a)

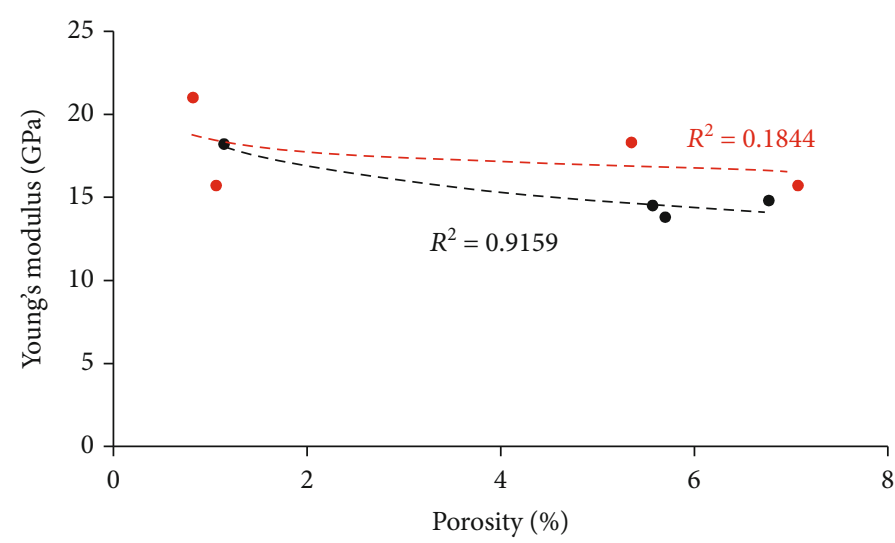

$$
\text { - UT }
$$

- LP

(b)

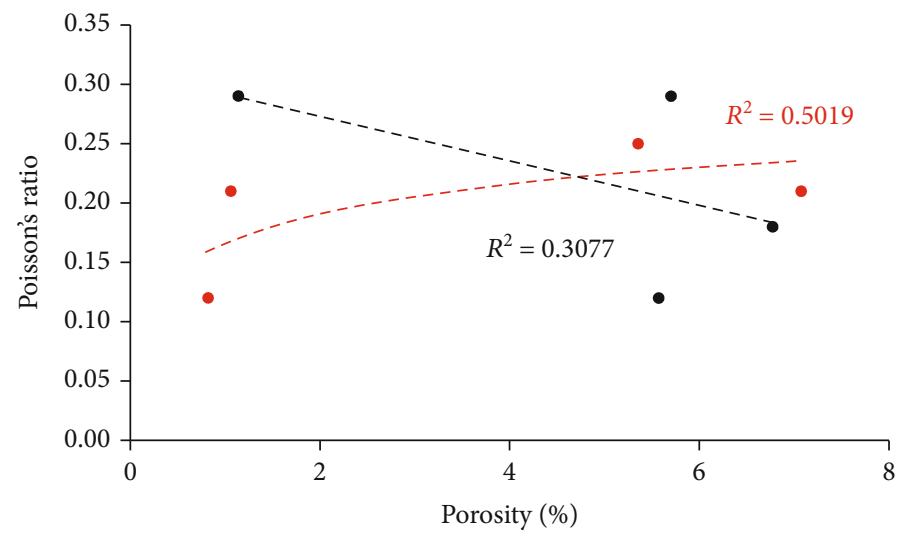

- UT

- LP

(c)

Figure 9: Continued. 


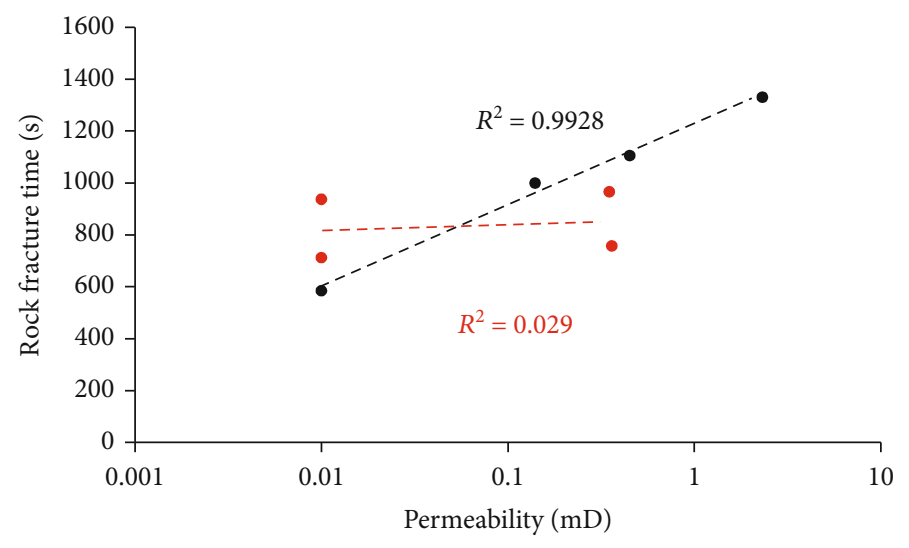

- UT

- LP

(d)

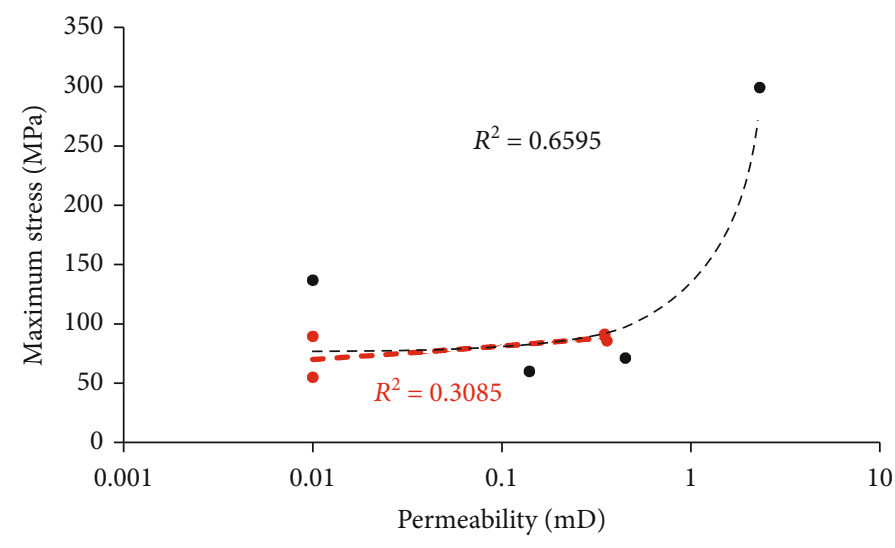

- UT

- LP

(e)

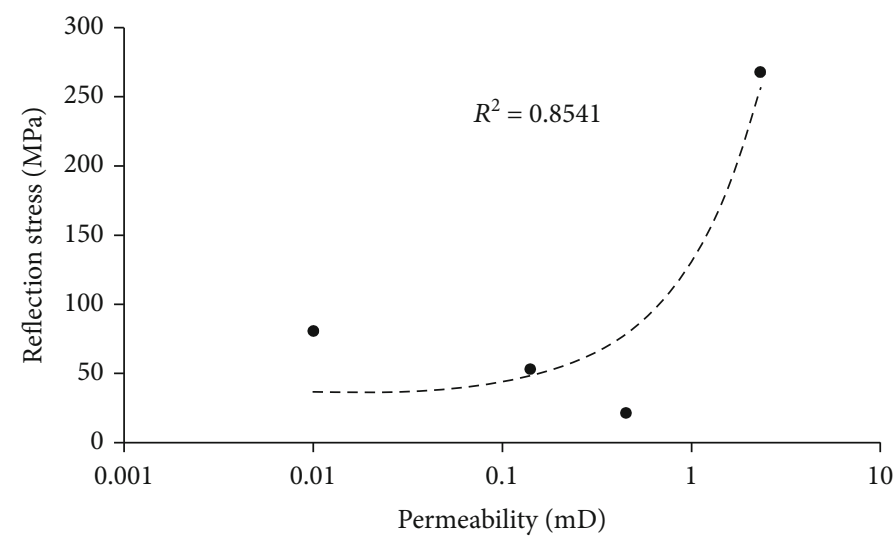

(f)

FIGURE 9: Relationships between petrophysical property and mechanical property parameters. UT: Upper Triassic; LP: Lower Permian.

Some rock mechanical parameters are also obtained by stress and strain history. Figure 8 shows the calculation methods of Young's modulus and Poisson's ratio, two typical rock mechanical parameters. With the increase of those two parameters, the resistance to compaction of the rock increases. Detailed data are shown in Table S1.
4.2. Relationships between Mechanical Property Parameters and Petrophysical Properties. The porosity and permeability can reflect the petrophysical rock properties. Therefore, we analyze the relationships between porosity/permeability and mechanical property parameters. The porosity and permeability of those eight samples are shown in Table S2. 


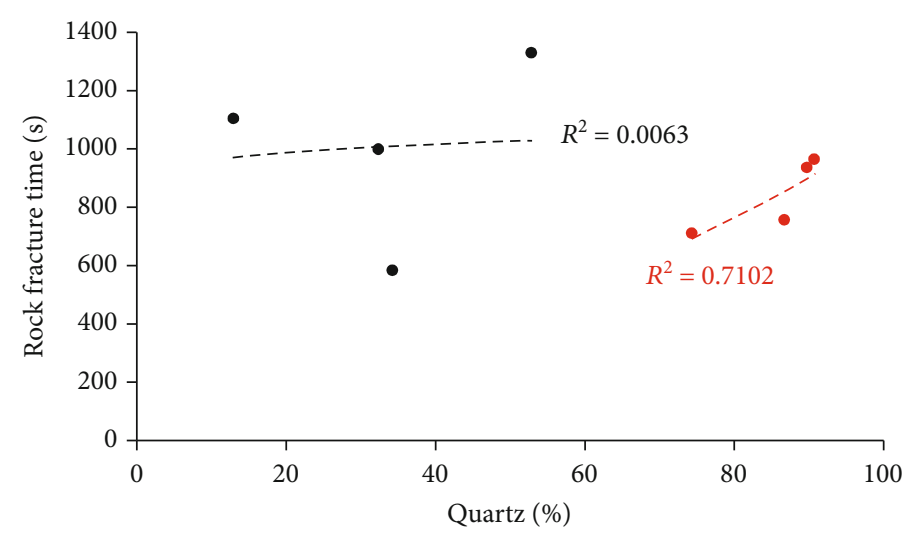

\section{- UT}

- LP

(a)

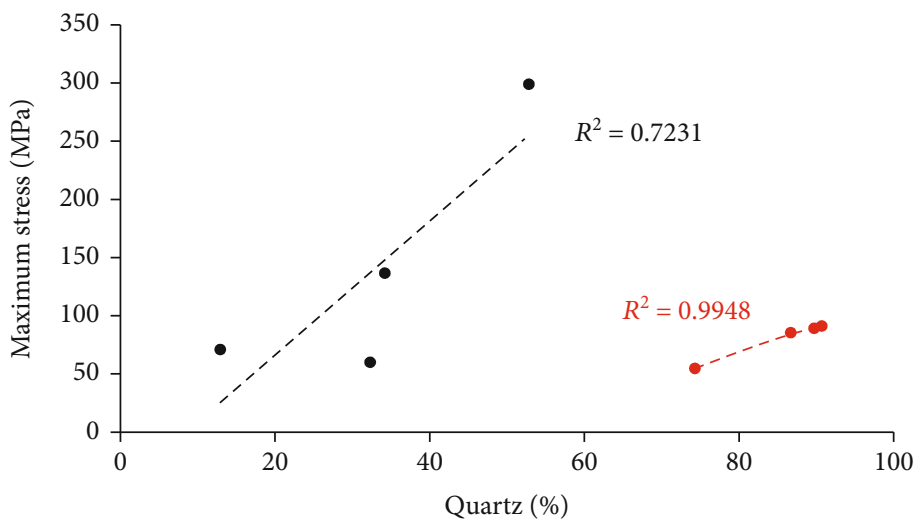

- UT

- LP

(b)

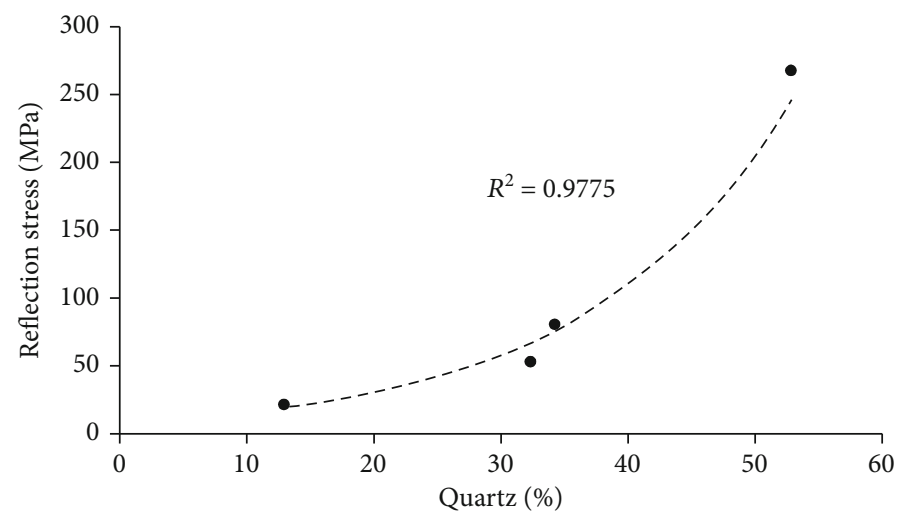

(c)

Figure 10: Continued. 


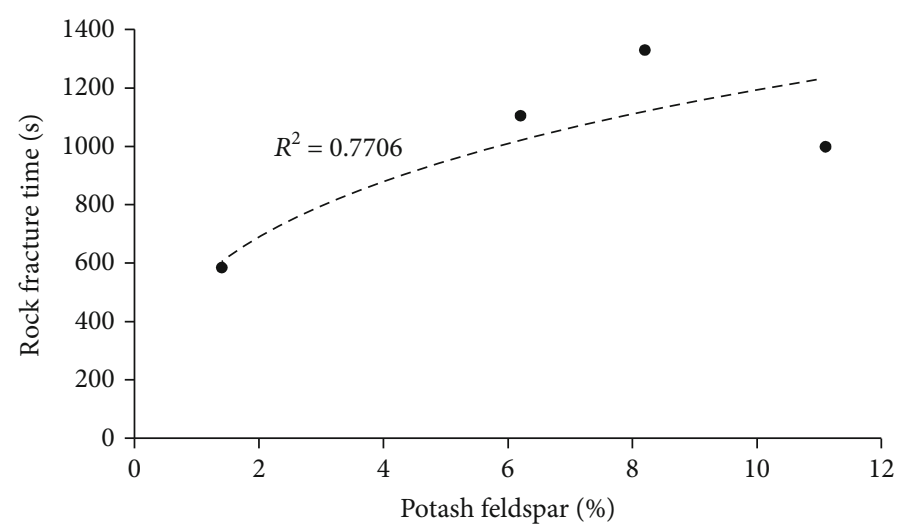

(d)

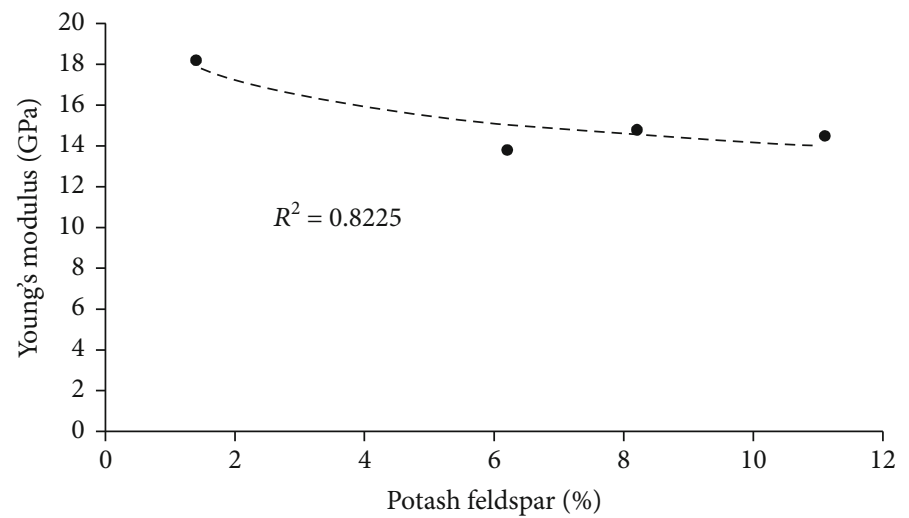

(e)

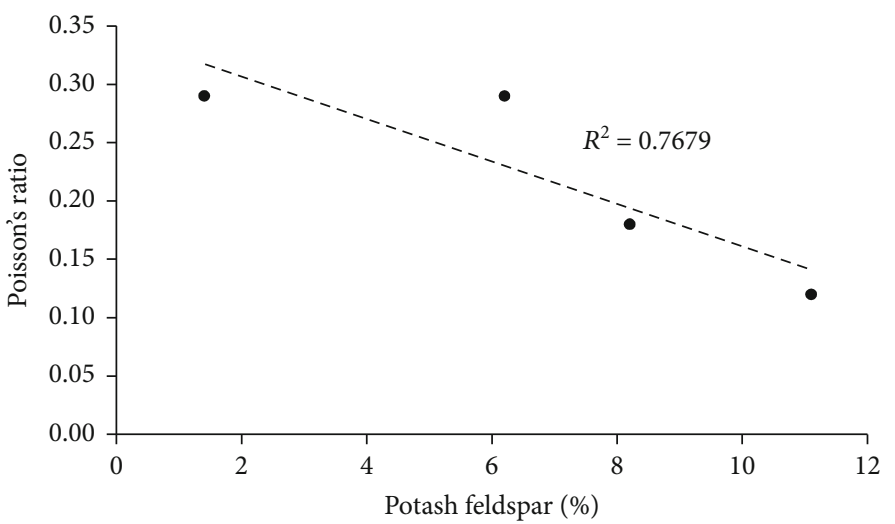

(f)

FIgURE 10: Continued. 


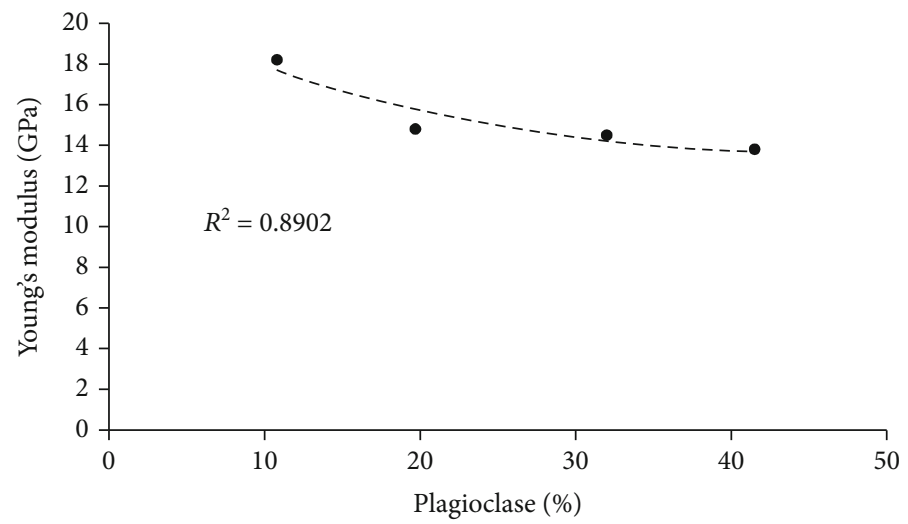

(g)

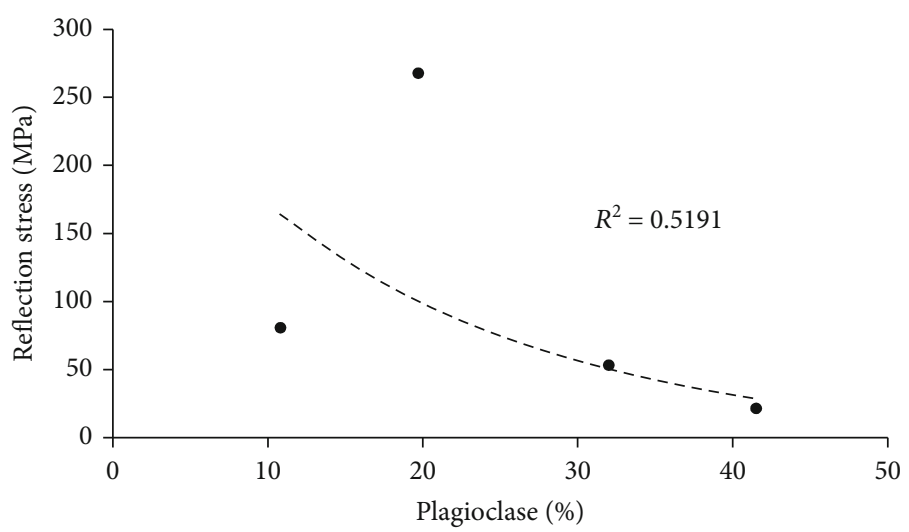

(h)

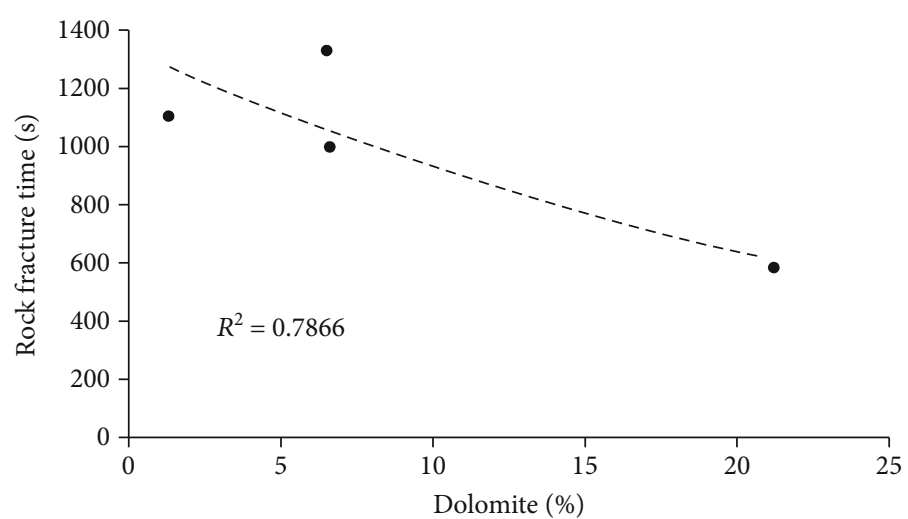

(i)

FIgURE 10: Continued. 


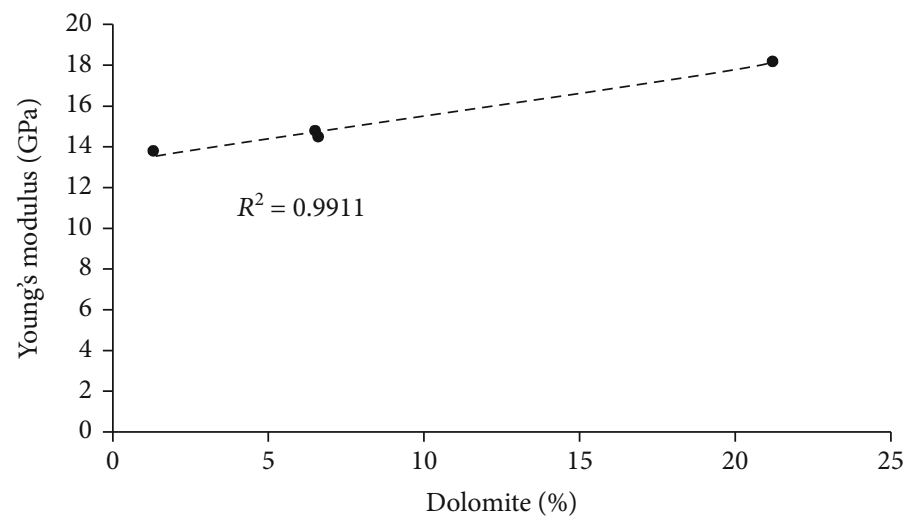

(j)

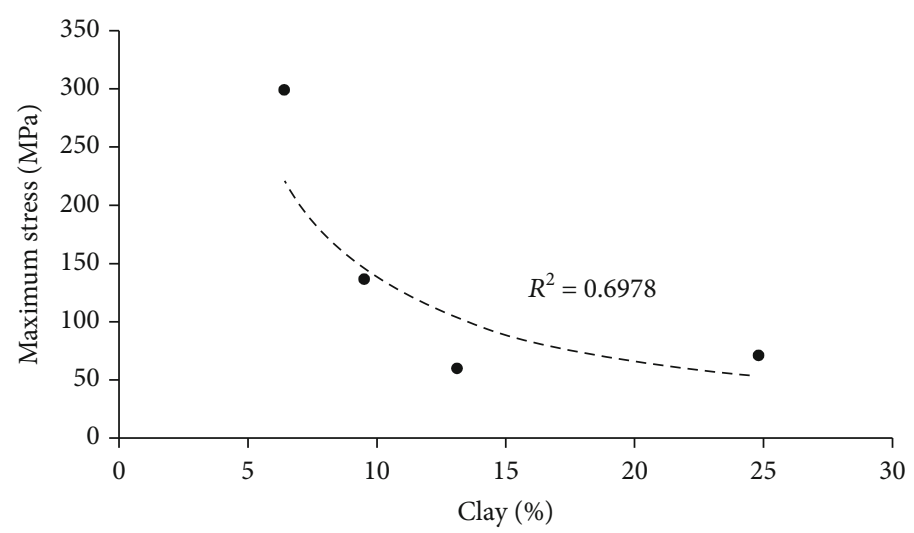

(k)

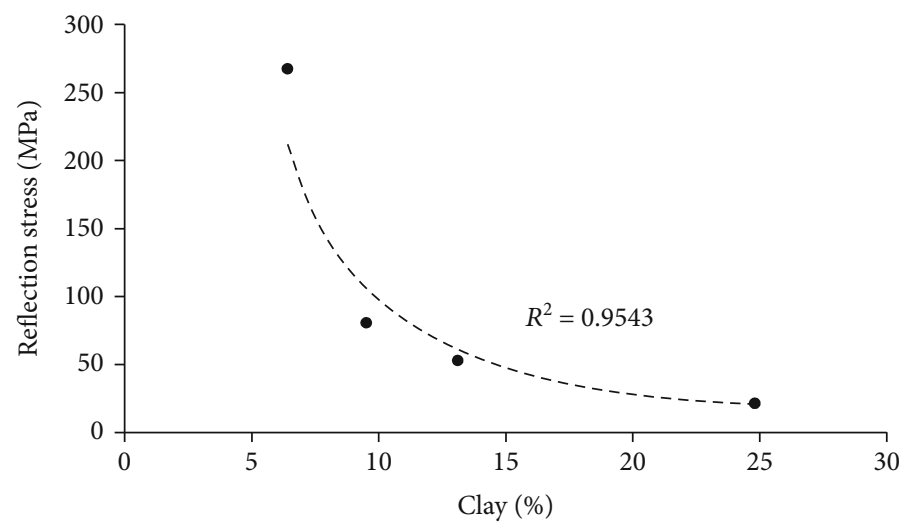

(1)

Figure 10: Relationships between mineral composition and mechanical property parameters. UT: Upper Triassic; LP: Lower Permian.

Figure 9(a) shows that the higher the porosity is, the longer the rock fracture time. Figures 9(b) and 9(c) demonstrate that porosity has negative correlations with Young's modulus and Poisson's ratio. Those figures illustrate that abundant pore space may resist the compression stress and enhance rocks' resistance ability. Similar to the porosity, the permeability also has positive relationships with mechanical property parameters. Besides, the Upper Triassic sandstones have a distinct response, while the Lower Permian ones do not have a typical trend, even having an opposite trend, reflecting that the former ones are more sensitive to the compression.
4.3. Relationships between Mechanical Property Parameters and Mineral Compositions. Mineral compositions are closely related to rock mechanical characteristics. The test results are shown in Table S2. Figures 10(a)-10(c) show a good positive correlation between quartz and rock fracture time, maximum stress, and reflection stress, indicating that the rocks abundant in quartz are more rigid. The Lower Permian sandstones only have quartz, calcite, and clay, and quartz plays a dominant role in the mineral content, whereas the calcite is in trace amounts. Therefore, it is not necessary to study the relationships between other minerals and rock mechanical properties. 
$R$-squared

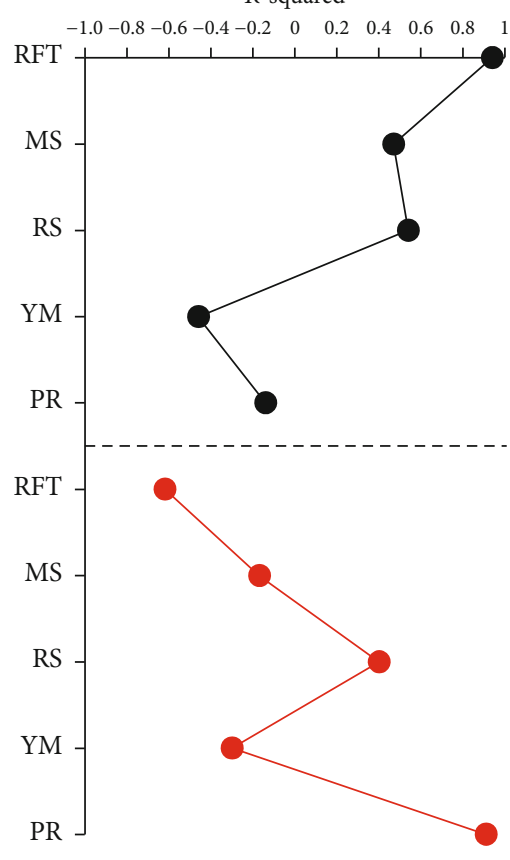

(a)

$R$-squared

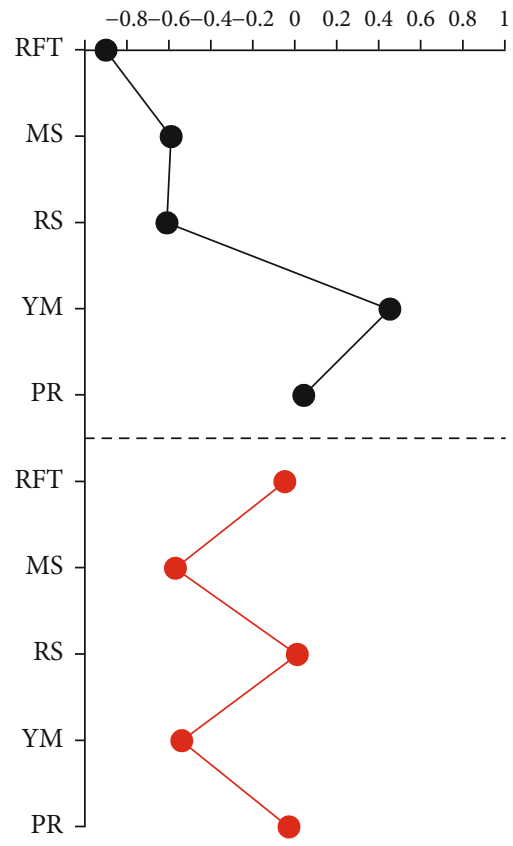

(c)
$R$-squared

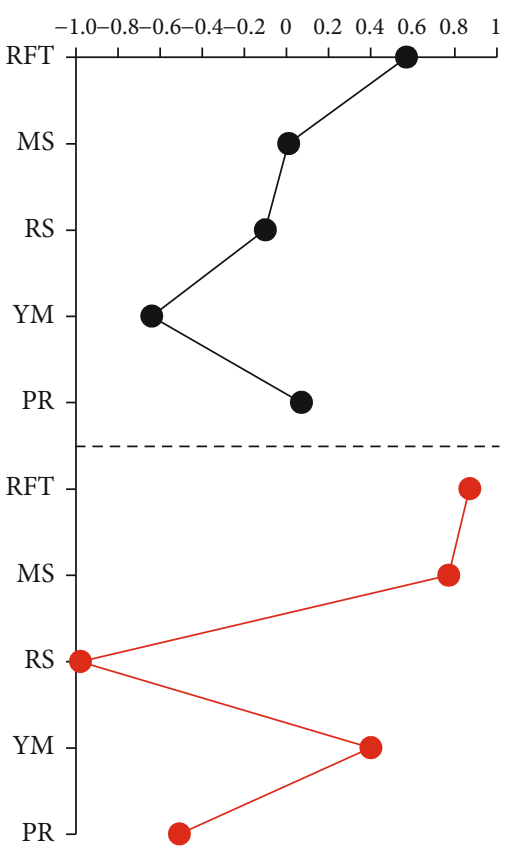

(b)

$R$-squared

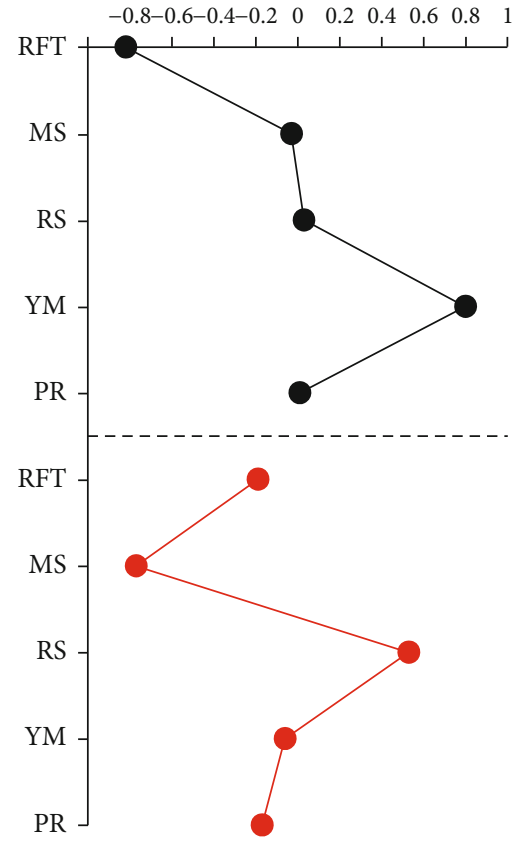

(d)

Figure 11: Continued. 


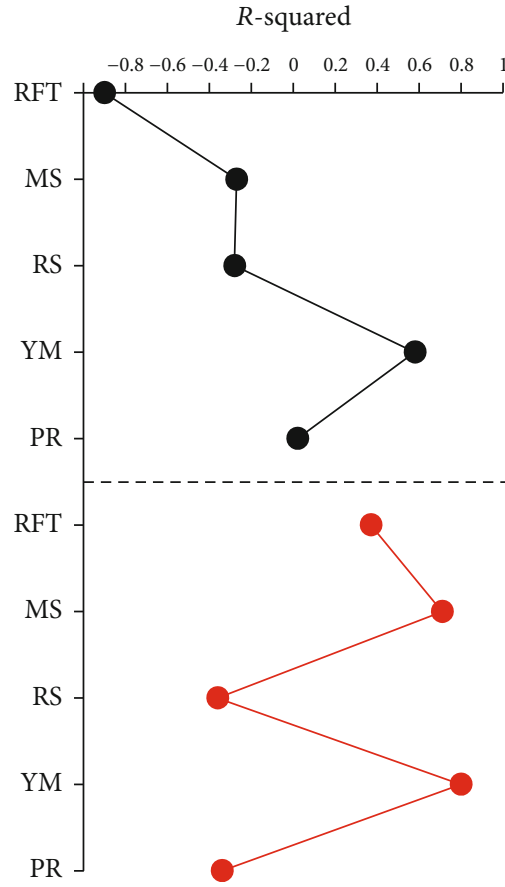

(e)

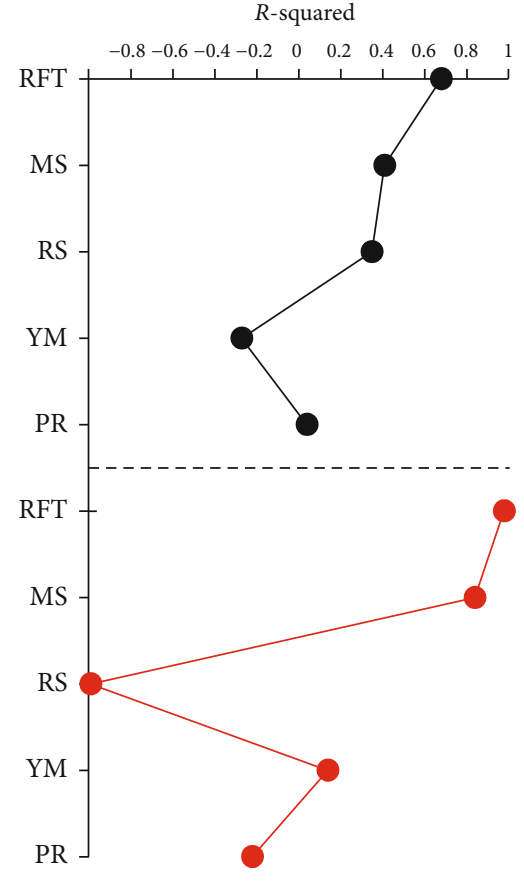

(f)

FIGURE 11: Relationships between elements (amount above 1\%) and mechanical properties: (a) silicon, (b) aluminum, (c) calcium, (d) ferrum, (e) magnesium, and (f) potassium. RFT: rock fracture time; MS: maximum stress; RS: reflection stress; YM: Young's modulus; PR: Poisson's ratio; black point: Upper Triassic; red point: Lower Permian.

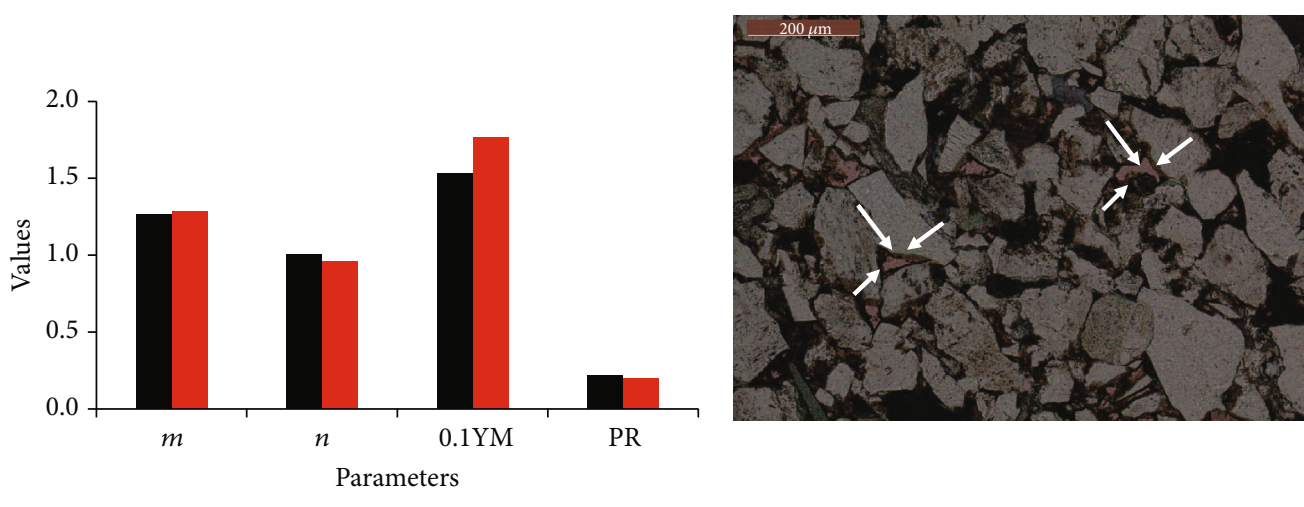

- UT

- LP

(a)

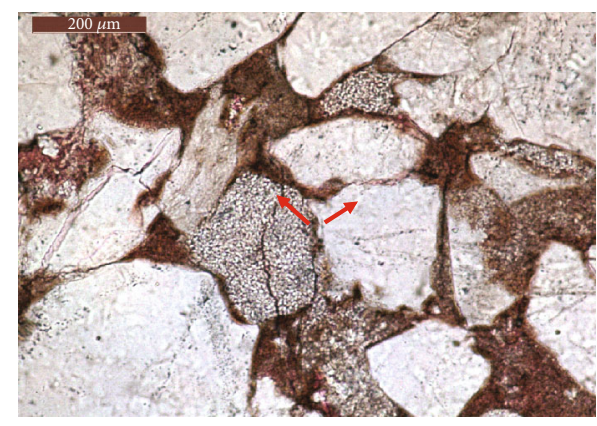

(c) (b)

Figure 12: (a) Histogram of the $m, n, 0.1$ times of the Young's modulus, and Poisson's ratio, (b) casting thin section of Upper Triassic sandstones, and (c) casting thin section of Lower Permian sandstones. UT: Upper Triassic; LP: Lower Permian. 


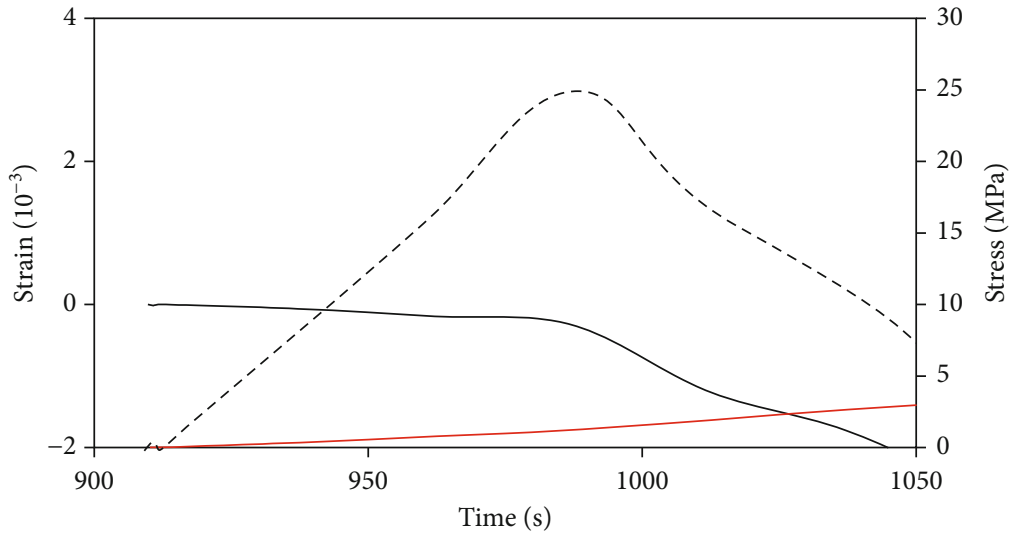

_ Axial strain

_ Principal stress

_ - - Radial strain

(a)

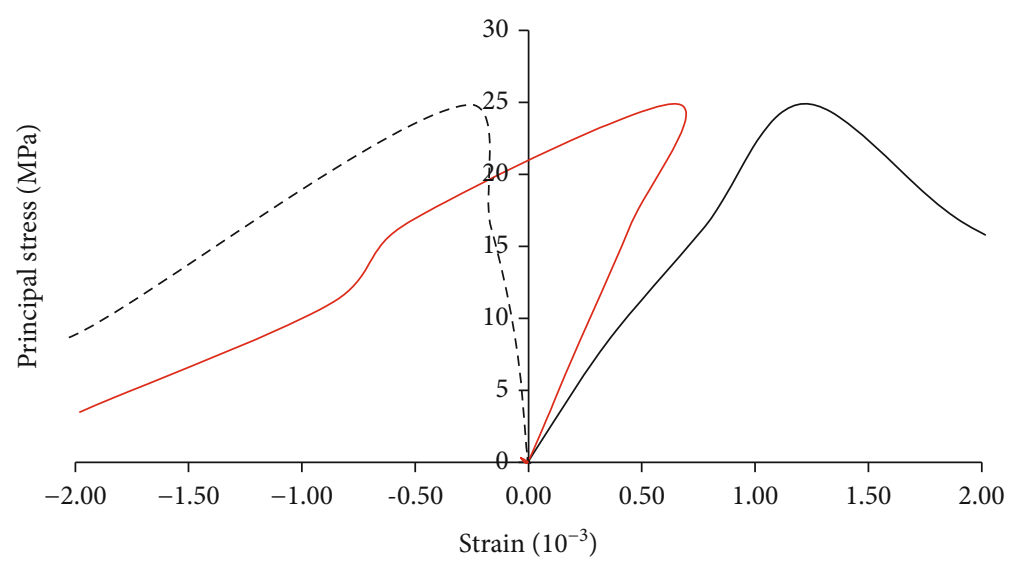

— Axial strain

- - - Radial strain

— Volumetric strain

(b)

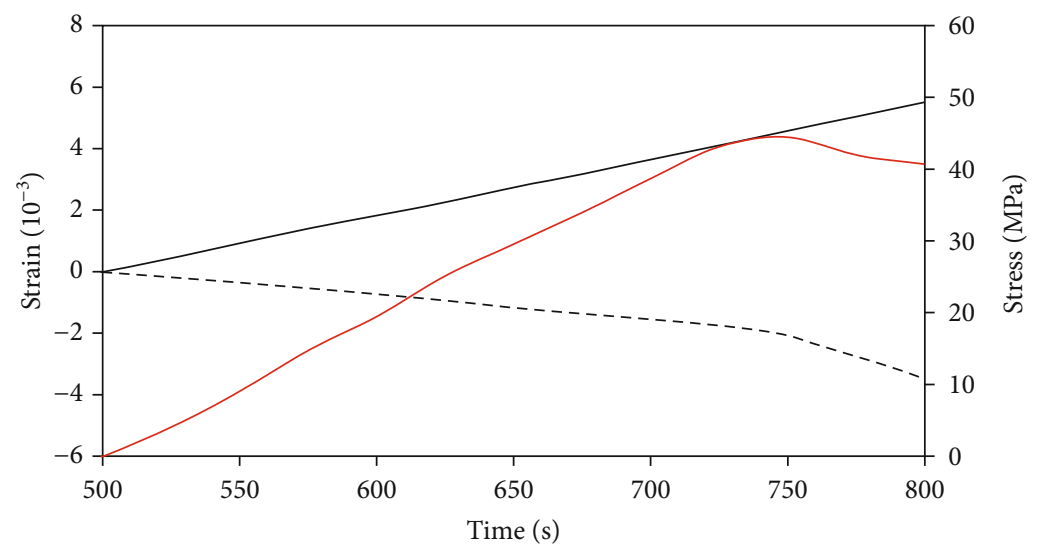

- Axial strain

- - - Radial strain

_ Principal stress

(c)

Figure 13: Continued. 


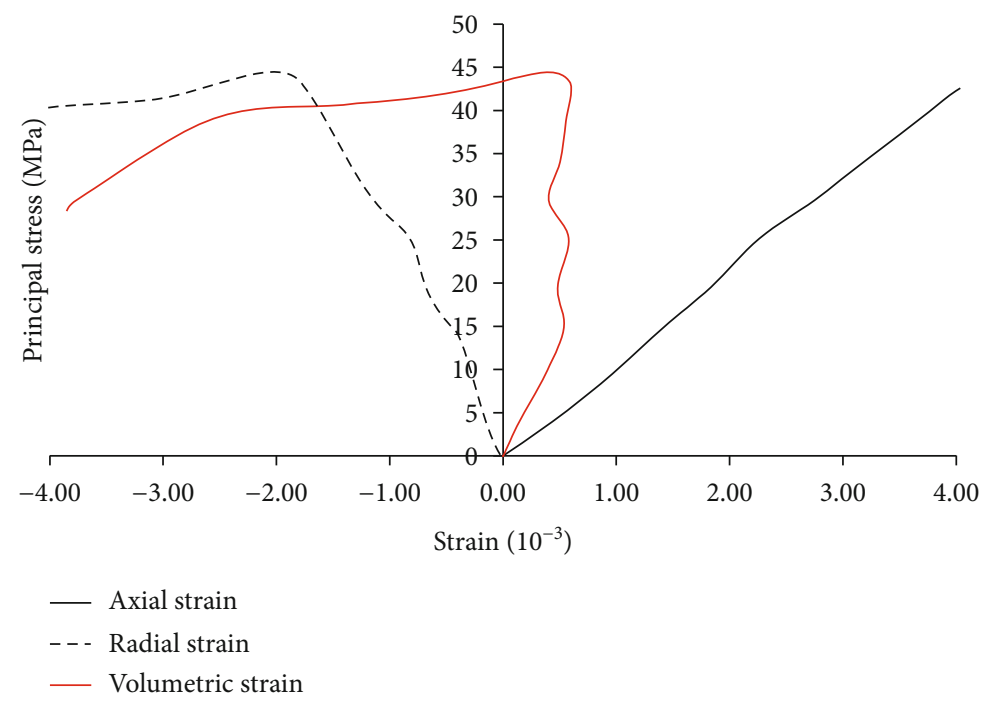

(d)

Figure 13: (a) Dynamic stress and strain history for shale 1, (b) stress and strain history for shale 1, (c) dynamic stress and strain history for shale 2, and (d) stress and strain history for shale 2 .

It can be seen from Figure 10(d) that potash feldspar has a good positive correlation with rock fracture time and dolomite also shows the same trend with Young's modulus (Figure 10(j)). However, when potash feldspar, plagioclase, dolomite, and clay increase, the rock mechanical properties gradually deteriorate (Figures 10(e)-10(i), 10(k), and 10(l)). Those different trends between potash feldspar, dolomite, and rock mechanical properties demonstrate that, although these minerals seem to have correlations with rock resistance, they do not impact the mechanical properties due to the restricted content. Those relatively abundant minerals, such as plagioclase and clay, may increase the plasticity of the rock.

4.4. Relationships between Mechanical Property Parameters and Elements. There is little research in the relationships between geochemical elements and mechanical properties; the data are shown in Table S3. Silicon is generally derived from terrigenous debris, which represents the presence of quartz. Silicon has a positive correlation with mechanical properties in Upper Triassic sandstones while is negatively correlated with mechanical properties in Lower Permian sandstones (Figure 11(a)). These trends indicate that abundant quartz may lead to the rocks becoming easy to crack. Aluminum is associated with feldspar and clay, and it has a positive correlation with mechanical properties (Figure 11(b)). Calcium is closely related to carbonate, low hardness, and easy cracking (Figure 11(c)). Ferrum, magnesium, and potassium are closely related to the silica formation environment. Therefore, they have the same or opposite trend with silicon (Figures 11(a) and 11(d)-11(f)). The proportion of the elements shown in Figure 11 are above $1.00 \%$; those below $1.00 \%$ are delivered in Figure S3.

4.5. Relationships between Mechanical Properties and RockElectrical Results. Figure 12(a) shows that lower Permian sandstones' anticompression ability is stronger than that of
Upper Triassic sandstones. Besides, as a large $m$ value represents complex pore networks, and large $n$ indicates weak water wettability, the Lower Permian sandstones have complex pore structure and abundant hydrophilic minerals (especially clay). Figures 11(b) and 11(c) show the reasons. Strong heterogeneity of the rocks generally represents a high proportion of clay minerals (Figure 2) and less pore space, which mean that the detrital minerals are close to each other and have a strong anticompression ability. Besides, strong water ability is also indicated by abundant hydrophilic minerals (illite and I/S mixed layer); those clays occlude the pores and increase the rocks' mechanical strength (Figure 11(c)).

4.6. Mechanical Property Differences between Sandstones and Shales. When compared with the sandstones' mechanical properties, those of the shales have some differences (Figures 6,7, and 13). The first one is that the shales' curves are more smooth than those of the sandstones, suggesting that shales have distinct plastic deformation. Besides, the shales' breaking time is much shorter than that of the sandstones, indicating that although the shales have precise plastic deformation, the shales are still easy to crack. However, there some myths still exist. For example, Young's modulus and Poisson's ratio for shales vary a lot, which means that further analysis needs to be done to research the mechanical properties of shales.

\section{Conclusions}

Mechanical properties of sandstones under uniaxial compression and microscopic geological features were systematically studied using the developed equipment. The mineral compositions, petrophysical properties, elements, and mechanical properties were determined, and how those microscopic geological features impact mechanical properties were investigated. The conclusions are as follows: 
(1) Quartz and plagioclase are essential minerals determining Upper Triassic sandstones' compositions, while quartz plays a dominant role in the Lower Permian sandstones

(2) Due to microcrack occurrence, the relationships between porosity and permeability of Upper Triassic sandstones are better than those of Lower Permian sandstones

(3) Observations have shown that silicon and aluminum are the main elements of those rocks. The rocks which have large porosity and permeability have a strong capacity of anticompression resistance. There are good consistencies between the mechanical behavior and the high proportion of rigid minerals

(4) The rocks which have abundant silicon and aluminum could better support the structural integrity of stones

(5) Strong structure heterogeneity and abundant hydrophilic minerals generally correspond to good anticompression ability.

\section{Data Availability}

The experimental data used to support the findings of this study are included in the manuscript and supplementary material.

\section{Conflicts of Interest}

The authors declare no conflict of interest.

\section{Acknowledgments}

This research was financially supported by the Open Fund of Key Laboratory of Coal Resources Exploration and Comprehensive Utilization, Ministry of Land and Resources (grant numbers KF2019-1, KF2020-2, and KF2021-7), Open Fund of Shaanxi Key Laboratory of Advanced Stimulation Technology for Oil \& Gas Reservoirs (grant number 20JS120), National Natural Science Foundation of China (grant numbers 51934005 and 52074226), and Young Science and Technology Talents Foundation of Shaanxi Province (grant number 2019KJXX-054).

\section{Supplementary Materials}

Table S1: mechanical property parameters of the samples. 1\#-4\#: Upper Triassic sandstones; 5\#-8\#: Upper Triassic sandstones. Table S2: petrophysical properties and mercury intrusion parameters of the samples. 1\#-4\#: Upper Triassic sandstones; 5\#-8\#: Upper Triassic sandstones. Table S3: element compositions of the samples. 1\#-4\#: Upper Triassic sandstones; 5\#-8\#: Upper Triassic sandstones. Figure S1: dynamic stress and strain history: (a) 1\#, (b) 3\#, (c) 4\#, (d) 6\#, (e) 7\#, and (f) 8\#. T: temperature; CP: confining pressure. Figure S2: stress and strain history: (a) 1\#, (b) 3\#, (c) 4\#, (d) 6\#, (e) 7\#, and (f) 8\#. Figure S3: relationships between elements (amount below 1\%) and mechanical properties: (a) sodium, (b) titanium, (c) phosphorus, (d) manganese, and (e) sulfur. RFT: rock fracture time; MS: maximum stress; RS: reflection stress; YM: Young's modulus; PR: Poisson's ratio; black point: Upper Triassic; red point: Lower Permian. (Supplementary Materials)

\section{References}

[1] W. Narr, "Fracture density in the deep subsurface: techniques with application to Point Arguello oil field," AAPG Bulletin, vol. 75, no. 8, pp. 1300-1323, 1991.

[2] G. Sheng, H. Zhao, Y. Su et al., "An analytical model to couple gas storage and transport capacity in organic matter with noncircular pores," Fuel, vol. 268, p. 117288, 2020.

[3] T. Ajayi, J. S. Gomes, and A. Bera, "A review of $\mathrm{CO}_{2}$ storage in geological formations emphasizing modeling, monitoring and capacity estimation approaches," Petroleum Science, vol. 16, pp. 1028-1063, 2019.

[4] I. Tomac and M. Sauter, "A review on challenges in the assessment of geomechanical rock performance for deep geothermal reservoir development," Renewable and Sustainable Energy Reviews, vol. 82, pp. 3972-3980, 2018.

[5] J. Su, G. Chai, L. Wang et al., "Pore-scale direct numerical simulation of particle transport in porous media," Chemical Engineering Science, vol. 199, pp. 613-627, 2019.

[6] H. Liu, W. Guo, D. Liu, S. Zhou, and J. Deng, "Authigenic embrittlement of marine shale in the process of diagenesis," Natural Gas Industry B, vol. 5, no. 6, pp. 575-582, 2018.

[7] S. Heng, X. Li, X. Liu, and Y. Chen, "Experimental study on the mechanical properties of bedding planes in shale," Journal of Natural Gas Science and Engineering, vol. 76, p. 103161, 2020.

[8] P. Calabrese and A. Gambassi, "Ageing properties of critical systems," Journal of Physics A: Mathematical and General, vol. 38, no. 18, pp. R133-R193, 2005.

[9] M. S. Masoudian, "Multiphysics of carbon dioxide sequestration in coalbeds: a review with a focus on geomechanical characteristics of coal," Journal of Rock Mechanics and Geotechnical Engineering, vol. 8, no. 1, pp. 93-112, 2016.

[10] G. Sheng, Y. Su, and W. Wang, "A new fractal approach for describing induced-fracture porosity/permeability/ compressibility in stimulated unconventional reservoirs," Journal of Petroleum Science and Engineering, vol. 179, pp. 855-866, 2019.

[11] S. Hong, J. Pan, T. Tyan, and P. Prasad, "Quasi-static crush behavior of aluminum honeycomb specimens under compression dominant combined loads," International Journal of Plasticity, vol. 22, no. 1, pp. 73-109, 2006.

[12] M. Zhang, S. Zhan, and Z. Jin, "Recovery mechanisms of hydrocarbon mixtures in organic and inorganic nanopores during pressure drawdown and $\mathrm{CO}_{2}$ injection from molecular perspectives," Chemical Engineering Journal, vol. 382, p. 122808, 2020.

[13] C. Zhu, M. He, M. Karakus, X. Cui, and Z. Tao, "Investigating toppling failure mechanism of anti-dip layered slope due to excavation by physical modelling," Rock Mechanics and Rock Engineering, vol. 53, pp. 5029-5050, 2020.

[14] K. Mogi, "Fracture and flow of rocks under high triaxial compression," Journal of Geophysical Research, vol. 76, no. 5, pp. 1255-1269, 1971. 
[15] P. Forquin, K. Safa, and G. Gary, "Influence of free water on the quasi-static and dynamic strength of concrete in confined compression tests," Cement and Concrete Research, vol. 40, no. 2, pp. 321-333, 2010.

[16] D. Liu, Z. Gu, R. Liang et al., "Impacts of pore-throat system on fractal characterization of tight sandstones," Geofluids, vol. 2020, Article ID 4941501, 17 pages, 2020.

[17] S. J. Mahler and P. R. Pessar, "Gender matters: ethnographers bring gender from the periphery toward the core of migration studies," International Migration Review, vol. 40, no. 1, pp. 2763, 2006.

[18] L. I. Meho and H. R. Tibbo, "Modeling the informationseeking behavior of social scientists: Ellis's study revisited," Journal of the American Society for Information Science and Technology, vol. 54, no. 6, pp. 570-587, 2003.

[19] J. Ren, L. Zhang, J. Ezekiel, S. Ren, and S. Meng, "Reservoir characteristics and productivity analysis of tight sand gas in Upper Paleozoic Ordos Basin China," Journal of Natural Gas Science and Engineering, vol. 19, pp. 244-250, 2014.

[20] T.-B. Zhao, W.-Y. Guo, Y.-L. Tan, Y.-C. Yin, L.-S. Cai, and A. J.-F. Pan, "Case studies of rock bursts under complicated geological conditions during multi-seam mining at a depth of 800 m," Rock Mechanics and Rock Engineering, vol. 51, no. 5, pp. 1539-1564, 2018.

[21] J. Su, G. Chai, L. Wang et al., "Direct numerical simulation of pore scale particle-water-oil transport in porous media," Journal of Petroleum Science and Engineering, vol. 180, pp. 159175, 2019.

[22] T. S. Ara, S. Talabani, H. H. Vaziri, and M. R. Islam, "In-depth investigation of the validity of the Archie equation in carbonate rocks. In SPE Production and Operations Symposium," in Society of Petroleum Engineers, Oklahoma City, Oklahoma, 2001.

[23] Z. Li, "Grouting effect on rock fracture using shear and seepage assessment," Construction and Building Materials, vol. 242, article 118131, 2020.

[24] Z. Li, S. Liu, W. Ren, J. Fang, Q. Zhu, and Z. Dun, “Multiscale laboratory study and numerical analysis of water-weakening effect on shale," Advances in Materials Science and Engineering, vol. 2020, Article ID 5263431, 14 pages, 2020.

[25] Q. Meng, H. Wang, M. Cai, W. Xu, X. Zhuang, and T. Rabczuk, "Three-dimensional mesoscale computational modeling of soil-rock mixtures with concave particles," Engineering Geology, vol. 277, article 105802, 2020.

[26] S. Zhan, Y. Su, Z. Jin, W. Wang, and L. Li, "Effect of water film on oil flow in quartz nanopores from molecular perspectives," Fuel, vol. 262, article 116560, 2020.

[27] Y. Wang, B. Zhang, S. H. Gao, and C. H. Li, "Investigation on the effect of freeze-thaw on fracture mode classification in marble subjected to multi-level cyclic loads," Theoretical and Applied Fracture Mechanics, vol. 111, p. 102847, 2021.

[28] J. S. Le Wang, Z. Gu, and L. Tang, "Numerical study on flow field and pollutant dispersion in an ideal street canyon within a real tree model at different wind velocities," Computers \& Mathematics with Applications, vol. 81, pp. 679-692, 2021.

[29] C. Zhu, X. D. Xu, and W. R. Liu, "Softening damage analysis of gypsum rock with water immersion time based on laboratory experiment," IEEE Access, vol. 7, pp. 125575-125585, 2019.

[30] C. Zhu, Z. H. Yan, Y. Lin, F. Xiong, and Z. Tao, "Design and application of a monitoring system for a deep railway foundation pit project," IEEE Access, vol. 7, pp. 107591-107601, 2019.
[31] D. Yin, S. Chen, Y. Ge, and R. Liu, "Mechanical properties of rock-coal bi-material samples with different lithologies under uniaxial loading," Journal of Materials Research and Technology, vol. 10, pp. 322-338, 2021.

[32] C. Zhu, M. C. He, Q. Yin, and X. H. Zhang, "Numerical simulation of rockfalls colliding with a gravel cushion with varying thicknesses and particle sizes," Geomechanics and Geophysics for Geo-Energy and Geo-Resources, vol. 7, no. 1, p. 11, 2021. 